\title{
A atualidade de um clássico: Educação física humanista de Vitor Marinho de Oliveira
}

\author{
Juliano de Souza
}

\section{RESUMO}

Educação física humanista, de Vitor Marinho de Oliveira, trata-se efetivamente de um clássico da educação física no Brasil. Neste texto, procuro revisitar essa obra e situá-lo diante de dois contextos epistemológicos desenhados na área de educação física: o embate historicamente firmado entre "ideologia" e "utopia" e o "novo movimento teórico" que vem esboçando alguns de seus traços distintivos no campo. $\mathrm{Na}$ primeira parte do manuscrito, pretendo restituir algumas pistas para entender por que essa obra foi silenciada na área. Já na segunda parte, procuro demonstrar em que medida a obra antecipa questões que podem ser proveitosamente somadas ao esforço de proposição de uma teoria reflexiva da educação física que traga os indivíduos e a ação social para o centro do processo investigativo. Como conclusão, ressalto que a obra Educação física humanista já na ocasião de seu aparecimento manifestava nuances de correspondência com a realidade social que se anunciava, mas ainda assim foi deixada de lado, até mesmo por seu mentor, em virtude de razões que ultrapassam a força interna dos argumentos e têm a ver com sistemas de crenças político-científicas.

PALAVRAS-CHAVE

epistemologia; teoria da educação física; teoria sociológica.

'Universidade Estadual de Maringá, Maringá, PR, Brasil. 


\title{
THE NEWS OF A CLASSIC: EDUCAÇÃO FÍSICA HUMANISTA OF VITOR MARINHO DE OLIVEIRA
}

\begin{abstract}
Educação física humanista of Vitor Marinho de Oliveira is effectively a classic of Physical Education in Brazil. In this text, I try to revisit this work and locate it in front of two epistemological contexts drawn in the area of Physical Education, one, the historically established conflict between "ideology" and "utopia" and another, the "new theoretical movement", which has flashed some of its distinctive features in the field. In the first part of the manuscript, I intend to retrace some clues to understand that this work was silenced in the area. In the second part, they try to demonstrate to what extent a work anticipates the questions that can be the object of a test on the proposal of a physical education reflexive theory that brings individuals and social action to the center of the investigative process. As a conclusion, I emphasize that the work Educação física humanista, already at the time of its onset, manifested nuances of correspondence with the social reality that was announced, but was nevertheless left aside, including by its mentor, for reasons beyond the internal strength of arguments and have to do with systems of political-scientific beliefs.
\end{abstract}

KEYWORDS

epistemology; physical education theory; sociological theory.

\section{LA ACTUALIDAD DE UN CLÁSICO: EDUCAÇÃO FÍSICA HUMANISTA DE VITOR MARINHO DE OLIVEIRA}

\section{RESUMEN}

Educação física humanista de Vitor Marinho de Oliveira se trata efectivamente de un clásico de la educación física en Brasil. En este texto, procuro revisar esa obra y ubicarla frente a dos contextos epistemológicos diseñados en el área de educación física, uno, el del embate históricamente firmado entre "ideología” y "utopía” y, otro, el "nuevo movimiento teórico" que viene esbozando algunos de sus rasgos distintivos en el campo. En la primera parte del manuscrito, pretendo restituir algunas pistas para entender que esa obra fue silenciada en el área. En la segunda parte, lo buscamos demostrar en qué medida una obra anticipa cuestiones que pueden ser objeto de un ensayo sobre la propuesta de una teoría reflexiva de la educación. Como conclusión, resalto que la obra Educación física bumanista ya en la ocasión de su aparición manifestaba matices de correspondencia con la realidad social que se anunciaba, pero aún así fue dejada de lado, incluso por su mentor, en virtud de razones que sobrepasan la fuerza interna de los argumentos y tienen que ver con sistemas de creencias político-científicas.

PALABRAS CLAVE

epistemología; teoría de la educación física; teoría sociológica. 


\section{INTRODUÇÃO}

$O$ "seu" clássico é aquele que não pode ser-lhe indiferente e que serve para definir a você próprio em relação e talvez em contraste com ele.

CALVINo, 1993, p. 13

Como analisado exemplarmente pelo sociólogo americano Jeffrey Alexander (1999), a importância de revisitar os clássicos é endêmica às ciências humanas e sociais. Diferentemente do que se nota no âmbito das ciências naturais, as humanidades, adverte o autor, não se pautam em uma abordagem cumulativa do conhecimento, mas em uma lógica revisionista. A principal tese defendida no texto é de que essa distinção entre as áreas não só deve ser respeitada como ela própria sugere que a existência de textos clássicos nas ciências humanas se dá em virtude de discordâncias de ordem não empírica sobre como explicar um mesmo domínio empírico. Para lançar elementos de sustentação a essa tese, Alexander (1999) recupera os embates que se deram no pós-Segunda Guerra acerca das interpretações que Talcott Parsons, ao elaborar sua teoria dos sistemas sociais, impôs a outros clássicos, especialmente a Durkheim e Weber. Como desfecho da trama, Alexander concluiu que a hegemonia teórica de Parsons só pôde ser abalada quando sua própria reinterpretação dos clássicos também o foi.

Por conseguinte, uma abordagem constituída nesses termos daria conta de justificar a existência e a importância dos clássicos para o desenvolvimento da atividade científica no campo da sociologia. Ademais, essa forma de abordagem seria sintomática de uma disciplina que também articula critérios de elaboração da verdade com base nos próprios enfrentamentos teóricos e metodológicos da área e que ultrapassam, portanto, o caráter das discussões empíricas (Alexander, 1999). Visto por essa perspectiva de discordância, em que está em jogo a possibilidade de compreensões particulares e interessadas dos textos, um clássico poderia ser definido como "[...] o resultado do primitivo esforço da exploração humana que goza de status privilegiado em face da exploração contemporânea no mesmo campo" (Alexander, 1999, p. 24). Essa definição, por sua vez, considera tanto o trato singular conferido pelos clássicos a determinados temas da vida social quanto prescreve a participação das gerações intelectuais vindouras na própria habilitação do classicismo desses (reduzidos) textos e autores em virtude da recorrência constante que fazem a esses nomes como marca indelével de seu métier e no intuito de contradizê-los, atualizá-los ou desdobrá-los.

Penso que essa proposta sumariamente exposta pode ser de interesse para a área de educação física, especialmente porque ela, em alguma medida, tem trabalhado em interface com a produção teórica levada a cabo no domínio da teoria social. Mais que isso, entendo que a retomada dos textos e autores clássicos próprios ao campo da educação física pode ser útil no intuito de potencializar a autorreflexividade nos domínios de pesquisa que aí se engendram de modo que possa mapear, por assim dizer, as tendências teóricas que iluminam o campo e, em um nível seguinte de esforço, estruturar tendências que indiquem para onde o campo pretende rumar. Sem esse tipo de preocupação, corre-se o sério risco de ofertar pensamentos no 
mercado de ideias apenas para participar de um jogo que mal se compreende ou, na melhor das hipóteses, que se está jogando sem saber justificar por que elegeu determinada estratégia e não outra.

Este artigo pretende ser uma contribuição à tentativa de destacar a importância dos clássicos da educação física brasileira, bem como à necessidade de revisitá-los para além de mera recursividade histórica. Nas páginas que se seguem, irei retomar um dos textos que se tornaram clássicos na área, assinado por Vitor Marinho de Oliveira com o título de Educação física humanista. O objetivo consiste em situar essa obra diante de dois contextos epistemológicos desenhados na área de educação física: o embate historicamente firmado entre "ideologia" e "utopia" e o "novo movimento teórico" que vem esboçando alguns de seus traços distintivos no campo. Na primeira parte do manuscrito, pretendo restituir algumas pistas para entender por que essa obra foi silenciada na área. Já na segunda parte, procuro demonstrar em que medida Educação física humanista antecipa questões que podem ser proveitosamente somadas ao esforço de proposição de uma teoria reflexiva da educação física que traga os indivíduos e a ação social para o centro do processo investigativo.

\section{EDUCAÇÃO FÍSICA HUMANISTA NO CONTEXTO DO EMBATE ENTRE “IDEOLOGIA” E “UTOPIA”}

É um raciocínio no mínimo simplista supor que o deslocamento epistemológico que se operou na trajetória intelectual de Vitor Marinho ao longo dos anos de 1980 se deva tão somente a uma tomada de posição racionalizada do autor no sentido de superação de um pensamento menos suficiente para outro mais suficiente. Basicamente, dois são os problemas com esse tipo de abordagem. Primeiro, a ação intelectual ou formas de pensamento não são desprovidas de contexto social (Mannheim, 1976), ou seja, são em alguma medida relacionais à composição de forças no interior do campo acadêmico e político (Bourdieu, 2003). Segundo, enquadrar as ideias no sentido estrito de progressão remete a uma atitude epistemológica positivista que bloqueia a possibilidade de revisitar os textos por meio de uma postura pragmática atenta igualmente às contribuições e limites das obras.

Ao retomar Educação física humanista, procuro não perder de vista esse pano de fundo e recair na atitude epistemológica aqui criticada. Por esse motivo também é que sou levado a discordar das razões explicativas que o próprio Vitor Marinho, sobretudo no livro Consenso e conflito da educação física brasileira - resultante de sua tese de doutorado, que foi disponibilizada à comunidade acadêmica em formato de livro no ano de 1994 - , passou a atribuir ao lugar de Educação física bumanista no contexto do embate teórico-político firmado na área de educação física escolar entre as correntes intelectuais por ele próprio definidas como "pedagogias do consenso e do conflito" (Oliveira, 1994). Parto do entendimento de que só é possível entender com precisão esse ponto de inflexão verificado na trajetória intelectual de Vitor Marinho quando devolvemos o agente ao contexto de transformações que tomavam de assalto a sociedade brasileira e se faziam repercutir no campo educacional e no campo da educação física. 
No intuito de matizar essa análise, convém agregar elementos teóricos fundantes da sociologia do conhecimento e ressaltar, em conformidade com Mannheim (1976), que em períodos de estabilidade social é muito improvável que estilos de pensamento e pontos de vistas antagônicos venham efetivamente à tona. É, pelo contrário, especialmente no contexto da crise que são reunidas as condições sociais necessárias para que determinados problemas possam emergir e serem formulados pelo pensamento e transpareçam como própria extensão das lutas de grupos sociais empiricamente organizados. Além disso, é no momento em que propriamente se abalam os fundamentos da sociedade autoritária que surge um espaço para que contratendências intelectuais se apresentem de forma mais explícita, evidenciando uma relação de saber-poder que ultrapassa a figura solitária e pretensamente autônoma do intelectual, sendo essa mesma relação, em vez disso, restituída e devidamente explicada muito mais em virtude do enfrentamento entre aqueles que procuram conservar a estrutura e aqueles que, de modo contrastante, idealizam e visam a sua subversão (Bourdieu, 2003).

O contexto em que Educação física humanista apareceu reporta a esses elementos. O texto apresentado em formato de livro no ano de 1985 foi resultado dos estudos de mestrado de Vitor Marinho entre os anos de 1977 e 1981 no Programa de Pós-Graduação em Educação da Universidade Federal do Rio de Janeiro (UFRJ), somado a "[...] uma pesquisa (1982) que se fundamentou na aplicação das categorias básicas utilizadas na dissertação [...]" (Oliveira, 1994, p. 124). O texto recupera o embate entre behaviorismo e psicologia humanista no campo da educação e apresenta uma proposta pedagógica para educação física escolar no cerne dessa última abordagem. Há que se considerar, nesse sentido, a própria influência da psicologia no âmbito da teoria educacional e os desdobramentos conflituosos que se materializaram na figura dos defensores e adeptos do comportamentalismo, da psicanálise, da psicologia genética, da psicologia humanista etc., todas essas variantes condensadas por Libâneo (1984) no polo das denominadas "tendências pedagógicas liberais", que posteriormente seriam contestadas pelas "tendências pedagógicas progressistas" e, mais a rigor, pela "pedagogia histórico-crítica" formulada por Saviani $(1983,1991)$, evidenciando o claro deslocamento de um debate de natureza psicológica, até então preponderante na área, para um debate de caráter mais sociológico, atento às lutas de classes e em correspondência com o próprio processo de abertura política e redemocratização no país.

Tais enfrentamentos de natureza teórico-política, por conseguinte, foram estendidos ao campo da educação física brasileira muito em razão de sua busca por legitimidade dentro do espaço escolar e da necessidade de sua afirmação como prática pedagógica transformadora. Vitor Marinho, por sua vez, não esteve à margem dessas movimentações e tanto no processo de produção de sua dissertação de mestrado, datada do final dos anos de 1970, dando origem ao livro Educação física humanista, como em sua pesquisa de doutoramento desenvolvida no final dos anos de 1980 e defendida também no Programa de Pós-Graduação em Educação na UFRJ em 1993, com o título As pedagogias do consenso e do conflito: a produção teórica da educação física brasileira nos anos 80, participou dos modos de pensar gestados no contexto histórico mais amplo e postos em confronto nas produções teóricas 
do campo educacional, do qual determinada ala da educação física, no intuito de colocar em xeque o paradigma biológico predominante na área, não sem interesses, se aproximou. O esforço de objetivação levado até certo ponto por Vitor Marinho no livro Consenso e conflito em relação ao aparecimento do texto Educação física humanista contempla alguns elementos teórico-políticos caros a essa dinâmica sugerida. O excerto é exemplar:

Uma releitura de Educação Física humanista, hoje, fez-me refletir acerca de suas limitações. A mais importante refere-se a um falso antagonismo entre as duas tendências estudadas. Digo falso porque elas se opõem, mas não no essencial. A humanista contesta o autoritarismo da comportamentalista sem, contudo, procurar suas raízes, que são sociais. Não apreende os fenômenos na sua essência, mantendo-se nas aparências. Ao não contestar o estabelecido socialmente, limita-se a uma proposta de caráter eminentemente psicologizante. Faz parte de um movimento que, inegavelmente, colaborou para que as aulas de ginástica se tornassem mais agradáveis, sem o perfil militarizado que as caracterizavam. Deixou transparecer, todavia, que este é o humanismo, e não apenas um humanismo. O humanismo que manifesta é de perfil ideologicamente liberal, adequando-se às diretrizes da Escola Nova. Ultimamente vem recebendo críticas bem-articuladas, encontrando-se, entre outras, os trabalhos de Farinatti (1992), Soares et al. (1992) e Mello e Bracht (1992). (Oliveira, 1994, p. 128)

A estratégia aqui adotada não consiste em jogar Vitor Marinho contra o próprio Vitor Marinho no desejo de procurar incoerências ao longo de sua produção intelectual. Vale repetir que essa redução ao texto é de pouco valor para a problematização posta, pois não permite entender que as tomadas de posição teórica dos intelectuais materializadas em seus argumentos transcendem a força ou a coerência interna dos próprios argumentos, como se determinados interesses sociais estivessem em suspenso e não penetrassem em suas atividades explicativas (Mannheim, 1976). Ao contrário disso, é justamente porque a intelligentsia se apresenta como uma "classe social desvinculada" que com efeito pode sintetizar em seu raio de ação todos os interesses que orientam a vida social, o que quer dizer, em outras palavras, que os intelectuais, "[...] além de portarem indubitavelmente a marca de sua afinidade específica de classe, são também determinados, em seus pontos de vista, por esse meio intelectual que contém todos os pontos de vista contraditórios" (Mannheim, 1976, p. 182).

Nesse sentido, os posicionamentos assumidos por Vitor Marinho em relação ao lugar de Educação física humanista no debate epistemológico da área requerem uma releitura considerando de fato os dois níveis de deslocamentos prevalecentes no ordenamento epistemológico e pedagógico da educação física como ele próprio objetivou no excerto revisitado, isto é, de uma postura eminentemente comportamentalista para outra humanista, e dessa última para um humanismo socialista revolucionário, porém interpretando essa movimentação não em teor de "consenso" e "conflito" como ele o faz, mas sim, pelo contrário, substituindo essas imagens por uma dinâmica analítica mais relacionista e constituída, portanto, em parâmetros de 
"ideologia" e "utopia", aqui entendidas como domínios que transcendem a realidade, mas que se distinguem à medida que uma visa à conservação da ordem e outra, a sua transformação (Mannheim, 1976).

Ao levar a cabo essa segunda proposta metodológica, torna-se necessário de imediato acrescentar ao quadro que está sendo composto algumas das repercussões e estranhamentos que Educaşão física humanista gerou entre a intelectualidade crítica da educação física participante, nos termos de Vitor Marinho (Oliveira, 1994), da "pedagogia do conflito". Em relação à Educação física humanista, Bracht (1992, p. 26) sugere:

O objetivo central da Educação Física torna-se, nesta concepção, a instrumentalização e movimentação do aluno para ocupar suas horas de lazer com atividades. E, de maneira que tal ocupação possa ocorrer de forma autônoma, crítica e criativa, existe a necessidade de utilizar formas variadas de movimentos corporais, diferenciando-as das atividades estereotipadas de alto nível. Adaptar, modificar, criar novas formas de movimento são as palavras da ordem.

De forma mais categórica, Soares et al. (1992, p. 55) argumentam:

Os movimentos renovadores da educação física do qual faz parte o movimento dito "humanista" na pedagogia se caracterizam pela presença de princípios filosóficos em torno do ser humano, sua identidade, valor, tendo como fundamento os limites e interesses do homem e surge como crítica a correntes oriundas da psicologia conhecidas como comportamentalistas. Essas correntes fundamentam as teorias de como o indivíduo aprende no esquema estímulo-resposta. Os princípios das correntes comportamentalistas informam a elaboração de taxionomias dos objetivos educacionais.

Os princípios veiculados pela pedagogia humanista foram tratados por Vitor Marinho de Oliveira no livro intitulado Educação Física Humanista, no qual o autor se baseia teoricamente na psicologia humanista de Maslow e Rogers. Essa perspectiva teórica é aquela que desloca a propriedade dada ao produto para o processo de ensino, introduzindo o princípio do ensino, "não diretivo". Situa os objetivos no plano geral da educação integral, onde o conteúdo passa a ser muito mais instrumento para promover relações interpessoais e facilitar o desenvolvimento da natureza, "em si boa", da criança.

Trata-se de posturas teóricas convergentes quanto ao conteúdo de Educação física humanista e que estão inscritas no âmbito das reflexões mais amplas gestadas por uma "família intelectual" dominante no campo da educação. As proposições de Saviani (1983) e de Libâneo (1984) foram, nesse sentido, mobilizadas como instrumental de desvelamento e alternativa político-pedagógica ao projeto acrítico, instrumental, tecnicista, conservador e ideológico em que a educação física escolar estaria pretensamente envolvida. Ademais, essa "família intelectual” formulou uma crítica às pedagogias tradicional, nova e tecnicista, elencando-as ao plano ideológico da conservação das estruturas sociais como estariam postas. Qualquer tipo de associação a ideias que acentuassem o caráter de liberdade individual foi interpretado 
como obstáculo ao projeto de transformação social e verdadeira emancipação, decorrentes de uma ação político-educacional pautada na pedagogia histórico-crítica. ${ }^{1}$

Ao que tudo indica, Vitor Marinho, ao produzir o material que deu origem a Consenso e conflito, levou bastante a sério as ideias em circulação no campo educacional e em ebulição no contexto político-social mais amplamente desenhado na sociedade brasileira. Assim se posicionando, realocou seu texto Educação física humanista, apesar dos avanços que ele mesmo reconheceu estarem presentes nessa abordagem, muito mais próximo ao polo da chamada "pedagogia do consenso", endossando a crítica de Valter Bracht (1992) ao assinalar que: "A Educação Física humanista, inegavelmente, encaminha uma proposta ancorada na teoria consensual do Liberalismo" (Oliveira, 1994, p. 161). Por sinal, não só Educação física bumanista foi associada a esse extremo, como também as abordagens de João Batista Freire (1989) e de João Paulo Subirá Medina (1983):

As propostas ditas humanistas, da forma como se apresentaram nos anos 1980, inscrevem-se aqui e desembocam na educação integral. A educação de corpo inteiro de João Batista, o meu humanismo pedagógico e, de uma certa forma, o revolucionarismo de Medina vinculam-se a essa concepção, que pode ser considerada como desencarnada socialmente, para utilizar uma expressão de Valter. (Oliveira, 1994, p, 183)

Em que pese, no entanto, esse ideal de educação integral, que em conformidade com as lentes teóricas adotadas por Vitor Marinho (Oliveira, 1994) remete sensivelmente aos pressupostos da pedagogia escolanovista, o autor imputa vantagens a essas propostas revisitadas em relação aos paradigmas biológico e tecnicista, sobretudo por superarem o dualismo "corpo-mente" e devolverem ao movimento humano suas dimensões históricas. Dito em outras palavras, há méritos nas abordagens humanistas, mas elas também são insuficientes porque não promovem a verdadeira mudança social preconizada. Visto o caso por esse ângulo teleológico, a discussão poderia ser encerrada nos termos da existência de uma consciência social superior. Mas as coisas são bem mais complexas do que esse último argumento sugere.

1 Em seu livro História das ideias pedagógicas no Brasil, de 2007, Saviani reitera e atualiza as análises já presentes em sua obra no início dos anos de 1980, especialmente ao problematizar o recrudescimento de uma pedagogia neoescolanovista. Diz o autor, nesse propósito: “O lema 'aprender a aprender', tão difundido na atualidade, remete ao núcleo das ideias pedagógicas escolanovistas. Com efeito, deslocando o eixo do processo educativo do aspecto lógico para o psicológico; dos conteúdos para os métodos; do professor para o aluno; do esforço para o interesse; da disciplina para a espontaneidade, configurou-se numa teoria pedagógica em que o mais importante não é ensinar e nem aprender algo, isto é, assimilar determinados conhecimentos. O importante é aprender a aprender, isto é, aprender a estudar, a buscar conhecimentos, a lidar com situações novas. E o papel do professor deixa de ser o daquele que ensina para ser o de auxiliar do aluno em seu próprio processo de aprendizagem" (Saviani, 2007, p. 431). 
Ao se aplicar, como sugere Mannheim (1976), o método que essa "família intelectual" utilizou para desnudar formas de conhecimento social ideológicas a ela própria, abre-se outra possibilidade de concatenar pensamento à existência, de modo que se possa obter uma elucidação mais ampla do problema do conhecimento e escapar à acepção de valor negativa do conceito de ideologia, que, assim tratado, aplicar-se-ia somente aos adversários, ao mesmo tempo em que imunizaria os descobridores desse método em sua tentativa de interpretação da história. Em outras palavras, e de forma mais peremptória, é possível afirmar:

O pensamento socialista, que até aqui vem desmascarando as utopias de todos os seus adversários como ideologias, jamais levantou o problema da determinação com respeito à sua própria posição. Jamais aplicou o método a si mesmo e nunca refreou seu desejo de ser absoluto. No entanto, é inevitável que também aqui o elemento utópico desapareça, com o aumento do sentido de determinação. (Mannheim, 1976, p. 273-274)

Argumentando nesses termos, Mannheim se afasta da concepção unilateral no trato com a ideologia (e também com a utopia) ao mesmo tempo em que se propõe a devolver uma dimensão autorreflexiva ao método que permitiu originalmente que o próprio problema da sociologia do conhecimento emergisse. Nesse percurso, Mannheim situa a utopia socialista-comunista como uma forma de mentalidade utópica que procura anular as utopias de seus antagonistas e denunciá-las como ideologias. Ademais, os grupos que partilham do pensar utópico estão tão interessados "[...] na destruição e na transformação de uma dada condição da sociedade que, mesmo involuntariamente, somente veem na situação os elementos que tendem a negá-la" (Mannheim, 1976, p. 67). Por essa razão é que esse tipo de pensamento se apresenta incapaz de uma diagnose realista do mundo social, dado o desejo apriorístico de mudar as coisas e subverter a ordem. Poder-se-ia dizer que, se os ideólogos estão demais comprometidos com a "realidade" para transformá-la, os utópicos estão demais envolvidos com a negação dessa mesma "realidade" para estabelecer um diagnóstico mais preciso.

Essa abordagem relacionista do problema da determinação do conhecimento, ao prever a impossibilidade de se constituir uma visão de mundo de forma absoluta, autorreferente, supraconsciente e supra-histórica, enfatizando, em vez disso, que todos os pontos de vista são relativos a uma dada situação e a outros olhares parciais e rivais sobre o mesmo mundo - o que não implica adotar um relativismo que nega haver regras de corroboração e testabilidade pautando a produção do conhecimento habilita outra perspectiva de revisitar o debate epistemológico na área de Educação Física em seu caráter histórico, mas também em seus diferentes pontos de inflexão estruturais. A abordagem sincrônica do debate epistemológico, tal como ganhou corpo no campo da educação física brasileira nos anos de 1980 e 1990, em relação íntima com os embates teórico-políticos do campo educacional, pode beneficiar-se desse tipo de análise na medida em que ela permite desnaturalizar as explicações acadêmicas tecidas para justificar a suficiência ou insuficiência de determinadas teorias e modelos pedagógicos voltados ao universo da educação física no Brasil. 
Estendendo esse método gnosiológico para restituir e imputar elementos explicativos de ordem extrateórica no intuito de entender por que as propostas humanistas para a educação física no Brasil perderam vez e, no processo de concorrência teórica no campo, foram então postas em estado de silêncio a ponto até mesmo de um de seus precursores a ter abandonado, vale confrontar um trecho conclusivo de Consenso e conflito de Vitor Marinho. Afirma, nesse propósito, o autor:

[...] os anos 1980 promoveram um verdadeiro inventário dos valores que têm colaborado para que a Educação Física e os seus agentes não contestem o estabelecido. Daí a ruptura promovida nesses anos. Conseguiu-se fazer distinções importantes entre autoritarismo e autoridade, entre individualismo e individualidade, apesar de carecer de um maior aprofundamento em outros conceitos fundamentais para uma pedagogia do conflito. [...]. É inegável que os anos 1980 incorporaram valores de uma pedagogia do conflito. Mesmo os discursos que se reduziam ao antiautoritarismo faziam sentido à época, pois representavam o máximo de consciência possível diante de uma ditadura que teimava em se perpetuar. $\mathrm{O}$ que não se pode mais aceitar é o mesmo discurso para os tempos atuais. A etapa para se lutar contra o autoritarismo em si já foi vencida. Cabe superá-la com a luta pela transição socialista. Não adianta ficarmos levantando bandeiras apenas pela moralidade, e sim contra a moral burguesa. Qualquer movimento popular necessita de um conteúdo ideológico (ou melhor, contraideológico) para não se correr o risco de assumir algum tipo de rebeldia juvenil que, longe de uma práxis, representa muito mais um ativismo inconsequente. (Oliveira, 1994, p. 186-187)

A verdadeira consciência transformadora (nos termos mannheimianos, um estado de espírito utópico), partilhada em diferentes graus pelos participantes dessa "família intelectual" mencionada no excerto, no propósito de desvelar o comprometimento das ideias e dos sistemas de pensamentos de seus rivais com a ordem social existente, atraiu assim para si o monopólio da crítica legítima à sociedade, aos modelos de escola, de ensino, fazer pedagógico etc., em uma configuração que, ao menos no Brasil, se legitimou primeiro no campo educacional e, algum tempo depois, se fez incidir no campo da educação física. A objetivação que Vitor Marinho impõe implicitamente no excerto em tela à Educação física humanista e a outras abordagens similares pode ser lida como um alinhamento a essa configuração teórica que emerge então como vitoriosa no campo educacional. Além disso, as próprias admoestações que Vitor Marinho recebeu no campo da educação física em relação à sua obra Educação física humanista contribuíram para que ele próprio, na construção de sua trajetória intelectual, reavaliasse sua crítica humanista como de valor pseudocrítico.

Entendo, no entanto, que interpretar esse processo ou ainda prospectá-lo em matéria de transição de uma pedagogia liberal para outra progressista, de uma pedagogia acrítica para outra verdadeiramente crítica, de uma pedagogia do consenso para outra do conflito, em suma, de uma pedagogia menos suficiente do ponto de vista da transformação social para outra supostamente mais suficiente, é uma 
atitude epistemológica paralisante e que pode ser revista e mais bem dimensionada teoricamente do ponto de vista da configuração relacional do "pensar ideológico" e do "pensar utópico". Essa última proposta possibilita também construir uma relação mais pragmática com as teorias pedagógicas, considerando igualmente seus recuos e avanços. No que se refere ao trato teórico de Educação física humanista e da perspectiva pedagógica que lhe é subjacente, a discussão aqui suscitada, porém de forma alguma esgotada, permite reabrir os caminhos que foram bloqueados para perceber e mobilizar os elementos de novidade teórica trazidos por Vitor Marinho de Oliveira na obra em questão e que ele próprio desacreditou. Nas páginas que se seguem, passo à reabilitação teórica desses elementos.

\section{EDUCAÇÃO FÍSICA HUMANISTA NO CONTEXTO DE UM “NOVO MOVIMENTO TEÓRICO”}

É de autoria também do sociólogo Jeffrey Alexander (1987) a conceituação distintiva de "novo movimento teórico" para designar a reorganização teórica que se operou no campo da sociologia internacional no decorrer dos anos de 1970. De acordo com o autor, como resposta ao estrutural-funcionalismo de Parsons no pós-Segunda Guerra, se fortaleceram, por um lado, as tendências de microteorização (interacionismo simbólico, etnometodologia, fenomenologia social etc.) e, por outro, as tendências de macroteorização social (em geral, releituras do marxismo e análises estruturais de corte weberiano). A unilateralidade dessas abordagens, todavia, começou a ser motivo de inquietação entre os teóricos expoentes da sociologia nos anos de 1970, sobretudo na França, Inglaterra e Alemanha. Em contramedida a essas tensões, novas teorias apareceram, como a teoria da prática de Bourdieu, a teoria da estruturação de Giddens e a teoria da ação comunicativa de Habermas. Mas o que essas teorias guardariam em comum?

Em linhas gerais, cada um desses quadros procurou produzir, ao seu modo, soluções teóricas conciliadoras para os problemas do equacionamento entre ação e estrutura, entre liberdade individual e determinismo estrutural, tensionamentos estes materializados, de longa data, nas diferentes escolas e tradições que conformam o campo das ciências sociais. Se no pós-guerra a teoria sociológica em reação ao funcionalismo potencializou seu discurso pendular de oposição entre "individualistas" e "coletivistas", os anos de 1970 viram surgir abordagens que propuseram grandes sínteses e a superação de antinomias (ação/estrutura, subjetivo/objetivo, indivíduo/ sociedade, micro/macro, parte/todo). É essa lógica de superação de dualismos e formulação de novas sínteses com base em uma atitude metodológica revisionista que Alexander (1987) qualificou como "novo movimento teórico".

Cabe ressaltar que esse esforço de reformulação do cenário teórico da sociologia apoiado no ponto de inflexão epistemológica evidenciado repercutiu para além dos epicentros que estiveram em sua origem, ou seja, se difundiu em escala internacional e para diferentes campos investigativos por meio da oferta, recepção e apropriação das teorias sociológicas protagonistas de tal movimento. No caso da educação física, o "novo movimento teórico" em alguma medida já foi recebido, 
muito embora ainda haja a necessidade de se investigar como isso se fez incidir sobre a área e quais os desafios que tem imposto e pode impor sobre a disciplina em questões teóricas, metodológicas e pedagógicas. Tenho como hipótese que esse movimento já fez surtir alguns de seus efeitos em domínios de pesquisa especializados da área e que trabalham em sintonia com as ciências sociais, a exemplo da sociologia do esporte. Sintomático do que está sendo aventado foi e tem sido a produção de uma série de pesquisas sobre o fenômeno esportivo moderno, tomando como base o modelo de análise sociológica dos campos de Bourdieu — um dos protagonistas do "novo movimento teórico".

Não obstante esse cenário de possibilidades abertas, penso que esse (não tão) "novo movimento teórico" ainda se encontra em estado de latência no campo da educação física, além de ainda não ter sido estendido e generalizado para tratar as questões macroteóricas da disciplina. Nesse propósito, um dos desafios que se apresentam àqueles que estão à frente da atividade científica no campo da educação física na perspectiva de interlocução com a teoria social é justamente potencializar o alcance do "novo movimento teórico" para estudar e dimensionar os problemas epistemológicos da profissão de uma forma mais extensiva e para além de suas dicotomias e tensões constitutivas. Há a necessidade também de se incorporar a esse modus operandi exercitado na área outros referenciais teóricos que se propuseram a concatenar sinteticamente questões estruturais com ação social, a exemplo dos trabalhos de Anthony Giddens ou de Ulrich Beck, autores pouco discutidos na disciplina. Outra tarefa imprescindível - e que também está sendo encorajada neste artigo - seria revisitar os textos teóricos clássicos da educação física brasileira no propósito de atualizá-los diante do debate epistemológico da área e reabilitar o núcleo de novidades teóricas que anteviram.

É nesse espírito que aqui estou retomando Educação física bumanista e passo a inventariar sua atualidade. Como discutido na seção anterior, a trajetória intelectual de Vitor Marinho no campo da educação física se deu com o deslocamento de uma abordagem de corte fenomenológico para outra mais estrutural. Educação física bumanista e Consenso e conflito são as balizas dessa transição. Foi ao tomar contato com o materialismo histórico-dialético em voga no campo da educação - e com suas repercussões já em vias de constituição na área de educação física - que Vitor Marinho avaliou com certo entusiasmo sua passagem da pedagogia do consenso à do conflito. Ao analisar essa inflexão pela perspectiva mannheimiana, poder-se-ia dizer que de uma obra para outra o autor transicionou de uma "utopia liberalista" para uma "utopia socialista". Ainda que isso seja verdade, conforme analisado anteriormente, entendo ser mais apropriado para o desfecho da argumentação proposta reconsiderar esse deslocamento intelectual em parâmetros de transição de uma abordagem com maior grau de realismo para outra com menor grau de realismo. Não por acaso, as chaves para compreender a atualidade de Educação física bumanista talvez se encontrem nessa última tomada de posição sugerida.

Antes, no entanto, de pontuar as questões que entendo atuais em Educação física humanista - e importantes serem somadas a uma teoria reflexiva da educação física -, julgo necessário deixar claro que meu esforço revisionista dedicado a tal obra se constrói à luz da teoria da modernização reflexiva de Beck e Giddens. 
Em outras palavras, procuro (re)ler e recuperar Educação física bumanista levando em consideração o núcleo de mudanças sociais de ordem objetiva e subjetiva que foram postas desigualmente em marcha nas diferentes regiões do globo desde pelo menos o fim da Guerra Fria, mudanças estas que se intensificaram a partir dos anos de 2000 e que têm feito valer cada vez mais o alcance analítico da noção beckiana de sociedade cosmopolita.

A propósito, para compreender com exatidão a conformação desse mundo social cosmopolita é necessário observar dois outros processos intimamente concatenados à sua emergência. Por um lado, tem-se o crescente processo de globalização de riscos com todas as suas possibilidades de organização da vida abertas, mas também com todos os seus inúmeros efeitos colaterais não planejados. Por outro lado, tem-se demarcado no tecido social o impulso individualizatório, ou processo de individualização, que impeliu os agentes cada vez mais a encontrarem "soluções biográficas" para contradições sistêmicas. O motor dessas mudanças paralelas operadas em escala micro e macro, em consonância com o que sugerem Beck (2011) e Giddens (2002), seria a reflexividade institucional, garantida, entre outras vias possíveis, pela generalização da ciência na vida cotidiana em uma dinâmica na qual os atores leigos foram habilitados como agentes competentes que não têm outra escolha senão escolher.

Esse processo de individualização, levado a patamar surpreendente no contexto da modernidade radicalizada, assume caráter central em uma teoria reflexiva da educação física, uma vez que a própria disciplina pode ser vista como uma subpolítica especializada que participou e tem participado da reflexividade da modernidade. Ao se pensar, por exemplo, na setorização dos estilos de vida de que fala Giddens (2002), estilos de vida estes plurais, que os sistemas abstratos ajudaram a construir e que os indivíduos tendem a tomar parte no sentido de planejamento de suas vidas, é no mínimo estranho negar à educação física, por meio de sua ação pedagógica concretizada por intermédio da escola, das academias de musculação e ginástica, dos clubes, das empresas de recreação, das escolas de iniciação esportiva etc., um papel decisivo na vida cotidiana dos agentes sociais. Não só a ação direta dos profissionais, mas os próprios canais de informação em que a educação física está em pauta (textos de caráter científico, manuais de atuação prática, revistas, jornais, programas de televisão, blogs etc.) repercutem uma série de conhecimentos associados ao corpo, atividade física, esporte, saúde, estética, lazer etc. que são mobilizados inventivamente pelos atores leigos.

Ademais, na etapa reflexiva da modernização, os próprios atores leigos, em alguma medida, se revestem de algum grau de perícia em uma série de assuntos e pautas cotidianas, ao menos para darem prosseguimento à sua vida e construírem uma "narrativa reflexiva do eu" que lhes confira margem de segurança ontológica e faça sentido a eles próprios. Soma-se a essa conjuntura o processo de destradicionalização (ou liberação de vínculos tradicionais) que concatena os indivíduos a um universo múltiplo de possibilidades existenciais que já não podem mais ser supridas tendo por referente concreto unidades de sobrevivências grupais típicas da modernização simples, a saber: família, classe, Estado-nação, Igreja etc. Não que essas referências deixam de existir, mas em um contexto de inseguranças genera- 
lizadas elas perdem seu monopólio, até porque o próprio redesenho institucional da segunda modernidade, com seus riscos e sistemas de controle e minimização de riscos, está voltado para indivíduos que são impelidos a tomarem decisões no curso de suas rotinas diárias, como meio muitas vezes de restabelecerem fontes de segurança e seguirem em frente. Em ambientes como esse, as relações sociais deixam de ser dadas e passam a ser rigorosamente construídas, negociadas, examinadas, uma a uma, por agentes competentes e autorais.

Sob tal panorama, uma teoria reflexiva da educação física atenta a essa mudança institucional, que não só revolucionou amplamente os estilos de vida e a dinâmica dos afetos como ela própria também foi resultado dessa reorganização das relações subjetivas, tem como desafio epistemológico fundante, talvez um dos principais, incluir em seu quadro explicativo o ímpeto de individualização em marcha na modernidade reflexiva e tão bem documentado nos escritos de Beck e Giddens. A consideração de que a fase reflexiva da modernização marca um momento histórico em que os atores, nunca como antes, foram e são arremessados a uma dinâmica de individualização crescente, é instrutiva na tentativa de redescobrir uma teoria da educação física que tenha mais elementos de correspondência com os processos sociais empiricamente observáveis. É aqui que os fundamentos de uma proposta humanista para a educação física escolar mostram sua força e atualidade.

Oportuno também notar que individualização não assume uma conotação valorativa para bem ou para mal. Não significa liberdade, tampouco egoísmo. Trata-se, em última instância, de um processo que teve vez em diferentes capítulos da história, mas que no contexto cosmopolita foi radicalizado a ponto de ser possível afirmar que na modernidade reflexiva "[...] se entra numa dinâmica institucional endereçada ao indivíduo, não ao grupo" (Beck, 2003, p. 69). Além disso, individualização não remete a um atomismo ingênuo ou isolamento social, e é por isso que uma abordagem teórica da educação física estruturada na esteira desse processo não significa, no campo da ação prática, renúncia à solidariedade social e atitude apolítica. O texto Educação física humanista pode emprestar elementos a essa compreensão:

O fato de fazermos a nossa proposta humanista à luz da psicologia não sugere, em hipótese alguma, que a educação possa ou deva ser reduzida ao plano individual. Este é importante quando interagindo com o social, em busca de uma superação dialética que permita ao homem ser o arquiteto de si mesmo e da construção de uma sociedade melhor e mais humana. (Oliveira, 1985, p. IX)

Na modernidade reflexiva, os atores têm sido, de fato, cada vez mais arquitetos de si mesmos. Por um lado, eles têm uma biografia reflexiva a desenvolverem no curso de sua vida. Por outro, há uma pluralidade de estilos de vida a serem por eles escolhidos, dentro de certos limites estruturais, é verdade, e que abrange ações cognoscentes que vão da esfera do trabalho à do lazer. Os "destinos sociais" passam a ser negociados individualmente e desigualdades de toda espécie se acirram. As instituições sociais da modernidade tardia, por sua vez, operam em uma lógica ambígua, produzindo riscos e também sua percepção. Riscos percebidos tornam-se motivo de controle e também permitem uma nova consciência ecológica e social. 
A subpolítica emerge. Há inúmeros avanços nas lutas por igualdade, mas investidas conservadoras e fundamentalismos não deixam de existir. A base de uma nova solidariedade está sendo posta e já não há mais necessidades de guias legítimos a fim de instrumentalizarem os agentes para revolução. Essa até mesmo já ocorre e se chama reflexividade.

Por conseguinte, se esse contexto delineado é verdadeiro, então a educação física e os seus processos pedagógicos podem ser reavaliados. Além do mais, se as teleologias deixam de ser ponto de partida na profissão, uma prática pedagógica em educação física com maior grau de correspondência social pode ser reabilitada, pois já não estaria comprometida com uma socialização desencarnada politicamente. Pelo contrário, é ao dar vazão às experiências corporais sempre plurais e conflitivas construídas pelos indivíduos em diferentes contextos de interação que uma subpolítica de valorização da alteridade poderia ser talvez desenvolvida. Além disso, o monopólio da reinvindicação legítima por justiça e igualdade no contexto da modernização reflexiva deixou de ser privilégio do ambiente escolar e universitário. Como diria Beck (2011), a política mudou definitivamente de lugar e deixou de ser um assunto de especialistas e burocratas. De forma mais assertiva, Giddens (1995, p. 303) argumenta:

[...] a política da vida é central hoje em dia, e com frequência precede as lutas pela igualdade. Poder-se-ia pensar que seria preciso emancipar a todos e então essas pessoas descobririam como viver. Acho, ao contrário, que é preciso descobrir como se quer viver frequentemente antes da emancipação, ou como parte da emancipação. Você tem que descobrir o sentido da vida, porque vale a pena viver, como se pode reparar as coisas, como se pode viver junto com os outros, como viver uma vida satisfatória, atingir uma identidade razoável e um espectro razoável de direitos.

As implicações desse tipo de leitura para pensar e tratar, por exemplo, da atividade pedagógica na educação física escolar são inúmeras. A principal dela talvez diga respeito ao deslocamento da ação pedagógica da figura do professor para a dos alunos, de modo que possa chamá-los para participarem de forma mais intensa das tomadas de decisão no processo educativo constituído nas aulas de educação física, o que, em outras palavras, significa dar espaço aos seus interesses culturais no que se refere ao envolvimento que constroem com o se-movimentar. Educação física humanista tem pioneirismo nesse tipo de abordagem, ao menos no Brasil. Ainda que por razões diferentes das que aqui estão sendo elencadas, Vitor Marinho, à luz da práxis humanista de Carl Rogers, apresentou um método de ensino para educação física escolar em contraposição ao modelo diretivo e comportamentalista expresso historicamente na área por meio da preocupação pedagógica de seus profissionais em desenvolverem a aptidão física dos alunos e ensinarem a técnica esportiva em moldes bastante tradicionais e instrumentais.

Educą̧ão física humanista questiona esse método diretivo que fez história na educação física mundial e encontrou refúgio privilegiado na manifestação pedagógica dessa disciplina no contexto escolar, até mesmo por conta do "[...] caráter eminente- 
mente prático de suas atividades e pela facilidade de medir seus resultados"(Oliveira, 1985, p. 49). Uma vez identificado o que parece ser um dos condicionantes internos da eficiência pelo qual o método diretivo se legitimou no âmbito das ações que ao largo da história foram atribuídas e definidas para a educação física nos currículos escolares, é possível dizer que a proposta humanista de Vitor Marinho, ancorada nos princípios da individualidade, potencial criativo, aprendizagem significativa e liberdade, lançou, com outras produções teóricas de inspiração similar, como o próprio autor reconheceu (Oliveira, 1994), as bases para uma destradicionalização dos métodos de ensino em educação física no Brasil. Esse mérito tem de ser imputado a Vitor Marinho no texto Educação física humanista. Os excertos que se seguem são reveladores dessa contribuição:

[...] as tarefas que pretendam promover uma aprendizagem realmente significativa para o aluno devem levá-lo a uma atitude consciente e relacionada com sua própria realidade, de modo a incorporar-se ao conjunto de seus conhecimentos. Não devemos conduzir as aulas em função daquilo que achamos importante, mas, a partir das necessidades do educando, criar situações que tenham possibilidade de integrar os objetivos do próprio aluno, promovendo uma autêntica mudança de comportamento. (Oliveira, 1985, p. 50)

Nas escolas, as metodologias utilizadas revelam um grau de autoritarismo indevido e tornam as atividades físicas um verdadeiro castigo, quando, na realidade, deviam causar prazer. Claro que não queremos sugerir um trabalho ginástico que, ocasionalmente, não proporcione algum desconforto. O que postulamos, em nome de uma real ação pedagógica, é que os exercícios sejam executados a partir de um impulso interior, onde o aluno sinta o movimento como sendo "seu", não dependendo de guias, modelos ou comandos. A satisfação em movimentar-se livremente e o envolvimento afetivo proporcionado por essa liberdade criam a verdadeira disciplina. Esta não será alcançada sob forma coercitiva, mas sim através da participação espontânea. (Oliveira, 1985, p. 57)

Conforme fica patente, uma opção humanista em educação física escolar permitiria colocar no centro do processo não conteúdos a serem transmitidos pela ação modeladora do professor, mas sim aqueles que se beneficiam diretamente dessa prática educativa: os seres humanos em processo de escolarização. Romper-se-ia, além disso, com a pedagogia diretiva e com o paradigma tecnicista que se fez preponderante na área, mas sem, todavia, desapossar o movimento humano de algumas de suas propriedades fundamentais, a despeito das dimensões biológicas e psicológicas tão decisivas para que a ação pedagógica em educação física possa ser efetivada. Educação física humanista, nesse sentido, não foi estruturada por seu mentor com intuito de fomentar dicotomias improdutivas. Já no início de seu livro, Vitor Marinho assevera que uma proposta humanista para a formação profissional não visa "[...] minimizar a importância dos estudos nas áreas médica e esportiva, pois é exatamente aí que se encontram os elementos de que se utiliza o professor para o cumprimento de sua tarefa" (Oliveira, 1985, p. 4-5). Assim sendo, 
somar preocupação e atitude humanistas ao fazer pedagógico da educação física não significa descaracterizar a área, mas, antes, implica uma tomada de posição que revaloriza o saber corporal e o se-movimentar dos indivíduos.

Em um contexto social pós-tradicional, esse esforço de microteorização, levado a rigor em Educação física humanista no propósito de trazer o indivíduo para o centro do processo pedagógico em tela, não é destituído de grau de realismo, especialmente porque seu agente causador, mesmo que sem os instrumentos teóricos mais sofisticados na ocasião, apresentou uma perspectiva pedagógica para a educação física com fortes vínculos de correspondências com as mudanças sociais em marcha na modernização reflexiva, sobretudo no que diz respeito à constituição de um curso de vida negociado pelos atores sociais de forma cada vez mais individualizada, mas que, em contrapartida, não denota frieza impessoal em um mundo de estranhos e pode até mesmo ser a base de uma nova solidariedade com o outro, de uma nova aprendizagem social.

Não obstante essa potencialidade subpolítica que Educação física humanista antecipa ou mesmo prospecta, uma tentativa de retomá-la no contexto do "novo movimento teórico", que sobretudo na última década tem se feito distribuir desigualmente no domínio de agendas de pesquisa ultraespecializadas, traduzidas especialmente nos esforços das gerações intelectuais mais jovens do campo da educação física, não pode prescindir de um trabalho de rearticulação de sua força analítica com novos arranjos epistemológicos, é verdade - principalmente ao devolver as experiências de socialização plurais ou, melhor dizendo, a agência humana ao contexto das transformações institucionais que foram radicalizadas na modernidade tardia.

Colocado sob outro aparato terminológico, penso que o tipo de proposta microteórica subjacente em Educação física bumanista poderia ganhar muito mais em realismo crítico se, diferentemente do que fez Vitor Marinho - isso até por conta dos instrumentos de conhecimento que dispunha no contexto de realização de seu estudo - , fosse associada ao desenho institucional e aos contornos macrossociológicos da sociedade mundial de risco, porém isso no contexto em questão, de fato, ainda não era possível. Em síntese, o que aqui foi sumariamente exposto se trata de um programa de pesquisa em aberto que preconiza soluções teóricas conciliadoras, ou seja, visa a uma fuga aos antagonismos teóricos pouco produtivos para atividade científica, a exemplo da polarização "micro-macro" que, tal como evidenciado no decorrer do texto, se fez demarcar nos dois momentos centrais da produção intelectual de Vitor Marinho de Oliveira.

\section{CONSIDERAÇÕES FINAIS}

Educação física humanista, pelas razões epistemológicas aventadas ao longo do texto, trata-se efetivamente de um clássico da educação física no Brasil e, mais que isso, faz parte da própria reflexividade engendrada nesse campo. Essa última condição pode ser sustentada na medida em que a educação física e os contextos nos quais ela se manifesta são apreciados como fenômenos circunscritos ao conjunto de transformações sociais mais amplas, que tanto deram formato à modernização reflexiva quanto são ao mesmo tempo expressão de sua existência. Entre essas 
mudanças se destacam os processos de destradicionalização e individualização que libertaram as relações sociais e as tomadas de posição dos indivíduos dos contextos de ação tradicionais. Em Educação física humanista, Vitor Marinho, ainda que por outros caminhos teóricos, associou essas condições ao espaço da educação física, porém as desacreditou ao se deslocar para outra ala teórica emergente nesse campo no início dos anos de 1990.

Por conseguinte, esse deslocamento visualizado em sua trajetória intelectual, conforme o tratamento teórico dado ao tema com base no método da sociologia do conhecimento, pode ser interpretado de duas maneiras. Uma delas é analisar esse fato como processo de transição de Vitor Marinho, em virtude do contexto histórico-político desenhado na sociedade brasileira no andar dos anos de 1980 e que impactou na elaboração da teoria crítica da educação repercutida na área de educação física - para uma forma de pensamento ou consciência social pretensamente como superior. A outra maneira é ler esse percurso em suas ambiguidades e correlações de forças políticas de modo que se possa considerar o projeto teórico de Educação física humanista abandonado por Vitor Marinho como uma abordagem que, na ocasião de seu aparecimento, já manifestava nuances de correspondência com a realidade social que se anunciava, mas que ainda assim foi deixada de lado por razões que ultrapassam a força interna dos argumentos e têm a ver com sistemas de crenças político-científicas.

Ao longo desse texto foram apresentados e acumulados argumentos em favor dessa segunda perspectiva, e isso constitui propriamente o aspecto metodológico da contribuição que aqui foi dada. No lastro dessa opção metodológica assumida, foram reunidos também ao longo do manuscrito elementos indicativos de que uma teoria reflexiva da educação física, nos marcos de um "novo movimento teórico", só poderá ser desenvolvida ao se abrir mão das teleologias autoritárias que se distribuem no campo e, mais que isso, ao se superar as tensões "micro-macro" e "natureza-sociedade", pares epistemológicos que têm associados a cada um de seus extremos sistemas de crenças particulares, ideologias e utopias. Por fim, ressalta-se a importância de revisitar os clássicos da educação física brasileira e problematizálos perante os delineamentos teóricos mais atuais. Isso talvez possa imputar novos avanços à área.

\section{REFERÊNCIAS}

Alexander, J. C. O novo movimento teórico. Revista Brasileira de Ciências Sociais, São Paulo: ANPOCS, v. 2, n. 4, p. 5-28, jun. 1987.

.A importância dos clássicos. In: Giddens, A.; Turner,J. (Orgs.). Teoria social hoje. São Paulo: Editora UNESP, 1999, p. 23-89.

BEcк, U. Liberdade ou capitalismo. São Paulo: Editora da UNESP, 2003. . Sociedade de risco: rumo a uma outra modernidade. São Paulo: Editora 34, 2011.

Bourdieu, P. El ofício de científico. Ciência de la ciência y reflexividad. Barcelona: Anagrama, 2003. 
BRAcht, V. Educaşão física e aprendizagem social. Porto Alegre: Magister, 1992. Calvino, I. Por que ler os clássicos. São Paulo: Ática, 1993.

Freire, J. B. Educação de corpo inteiro: teoria e prática da educação física. São Paulo: Scipione, 1989.

Giddens, A. Entrevista com Anthony Giddens. Estudos Históricos, Rio de Janeiro: FGV, v. 8, n. 16, p. 291-305, 1995. . Modernidade e identidade. Rio de Janeiro: Zahar, 2002.

Libâneo,J. C. Democratização da escola pública: a pedagogia crítico-social dos conteúdos. São Paulo: Loyola, 1984.

Mannheim, K. Ideologia e utopia. 3. ed. Rio de Janeiro: Zahar, 1976.

Medina, J. P. A educação física cuida do corpo... e mente. Campinas: Papirus, 1983.

Oliveira, V. M. Educação física humanista. Rio de Janeiro: Ao Livro Técnico, 1985. - As pedagogias do consenso e do conflito: a produção teórica da educação física brasileira nos anos 80.1993. Tese (Doutorado em Educação) - Universidade Federal do Rio de Janeiro, Rio de Janeiro, 1993. . Consenso e conflito da educação física brasileira. Campinas: Papirus, 1994.

SAviani, D. Escola e democracia: teorias da educação, curvatura da vara, onze teses sobre educação e política. Campinas: Autores Associados, 1983.

. Pedagogia histórico-crítica: primeiras aproximações. Campinas: Autores Associados, 1991.

. História das ideias pedagógicas no Brasil. Campinas: Autores Associados, 2007.

Soares, C. L. et al. Metodologia do ensino da educação física. São Paulo: Cortez, 1992.

\section{SOBRE O AUTOR}

Juliano DE Souza é doutor em educação física pela Universidade Federal do Paraná (UFPR). Professor da Universidade Estadual de Maringá (UEM). E-mail: julianoedf@yahoo.com.br

Recebido em 19 de maio de 2017 Aprovado em 12 de setembro de 2017 